Landslides (2016) 13:211-214 DOI 10.1007/s10346-016-0690-x Received: 22 February 2016 Accepted: 22 February 2016 Published online: 30 March 2016 (c) Springer-Verlag Berlin Heidelberg 2016
Kyoji Sassa

\section{Implementation of the ISDR-ICL Sendai Partnerships 2015-2025 for global promotion of understanding and reducing landslide disaster risk}

The ISDR-ICL SENDAI Partnerships 2015-2025

The International Consortium on Landslides (ICL) was founded on 21 January 2002 in Kyoto, Japan. The ICL proposed a thematic session on landslides to take place at the Second United Nations World Congress on Disaster Reduction (WCDR), Kobe, Japan in 2005. Based on the outcome of this session Letter of Intent 2005, the 2006 Tokyo Action Plan-strengthening research and learning on landslide and related earth system disasters for global risk preparedness was adopted at the United Nations University, Tokyo, Japan (Sassa 2006). The Tokyo Action Plan proposed the World Landslide Forum (WLF) held every 3 years, the identification of World Centres of Excellence on Landslide Risk Reduction (WCoE) at each World Landslide Forum, and the establishment of the IPL Global Promotion Committee (IPL-GPC) to manage the International Programme on Landslides (IPL), a programme of the ICL for ISDR. ICL organized a 1oth Anniversary Conference on 17-20 January 2012 in Kyoto when the ICL Strategic plan 20122021-To create a safer geoenvironment was adopted (Sassa 2012). At this conference, ICL examined the 2014 Beijing Declaration to be adopted by the World Landslide Forum 3 in Beijing, China, in 2014 and the draft of ICL-IPL Sendai Partnerships 2015-2025 to be proposed in Sendai, Japan, in March 2015. A high-level panel discussion Initiative to create a safer geoenvironment toward WCDRR 2015 and forward was held at the Third World Landslide Forum in Beijing, 2014. Figure 1 is a group photo after the panel discussion including the Director-General of UNESCO Ms. Irina Bokova.

\section{Establishment of the ISDR-ICL Sendai Partnerships 2015-2025}

ICL was a co-organizer of the Working Session No. 4 (WS 4) Underlying Risk Factors (Priority No. 4 of the Hyogo Framework for Action) together with MLIT, UNESCO, and other organizations under the initiative of ISDR. ICL proposed the Sendai Partnerships on Landslides to the session, and this was accepted on 16 March 2015 in the morning session of the Third World Conference on Disaster Risk Reduction at the Sendai International Center, Sendai, Japan. The title of Sendai partnerships consists of three parts.

Header: Voluntary commitment to the World Conference on Disaster Risk Reduction, Sendai, Japan, 2015

Main title: ISDR-ICL SENDAI PARTNERSHIPS 2015-2025 FOR GLOBAL PROMOTION OF UNDERSTANDING AND REDUCING LANDSLIDE DISASTER RISK

Subtitle: Tools for Implementing and Monitoring the Post2015 Framework for Disaster Risk Reduction and the Sustainable Development Goals
The 16 intergovernmental, international, and national organizations signed the Sendai Partnerships at Sendai on 16 March 2015, and the World Meteorological Organization (WMO) signed in 2016. The 17 signatory organizations are the following:

1. International Consortium on Landslides (ICL)

2. United Nations Office for Disaster Risk Reduction (UNISDR)

3. United Nations Educational, Scientific and Cultural Organization (UNESCO)

4. Food and Agriculture Organization of the United Nations (FAO)

5. United Nations University (UNU)

6. World Meteological Organization (WMO)

7. International Council for Science (ICSU)

8. World Federation of Engineering Organizations (WFEO)

9. International Union of Geological Sciences (IUGS)

10. International Union of Geodesy and Geophysics (IUGG)

11. Cabinet Office, Government of Japan (CAO)

12. Ministry of Education, Culture, Sports, Science and Technology, Government of Japan (MEXT)

13. Kyoto University, Japan

14. Science Council of Japan

15. National Civil Protection Department, Italian Presidency of the Council of Ministers, Government of Italy

16. National Protection and Rescue Directorate, Republic of Croatia

17. Global Risk Forum (GRF) Davos.

Figure 2 presents a group photo of signers and participants in the Sendai Partnerships signing ceremony.

The World Landslide Forum 4 and the high-level panel discussion ICL is organizing the Fourth World Landslide Forum on 29 May to 2 June 2017 in Ljubljana, Slovenia, under the honorary patronage of his Excellency Mr. Borut Pahor, President of the Republic of Slovenia. ICL invited leaders of 17 signatory organizations to serve as honorary chairpersons of the organizing committee of WLF 4 and has already obtained confirmation from most of them. The opening ceremony will be organized on 30 May 2017. Two opening addresses are to be presented from ICL President and Prime Minister of the Republic of Slovenia, then, Ms. Irina Bokova, Director-General of UNESCO will present the opening speech on the UNESCO support to ICL and IPL activities as below.

\section{Opening Address:}

World Landslide Forum-ICL's triennial a mainstream conference 


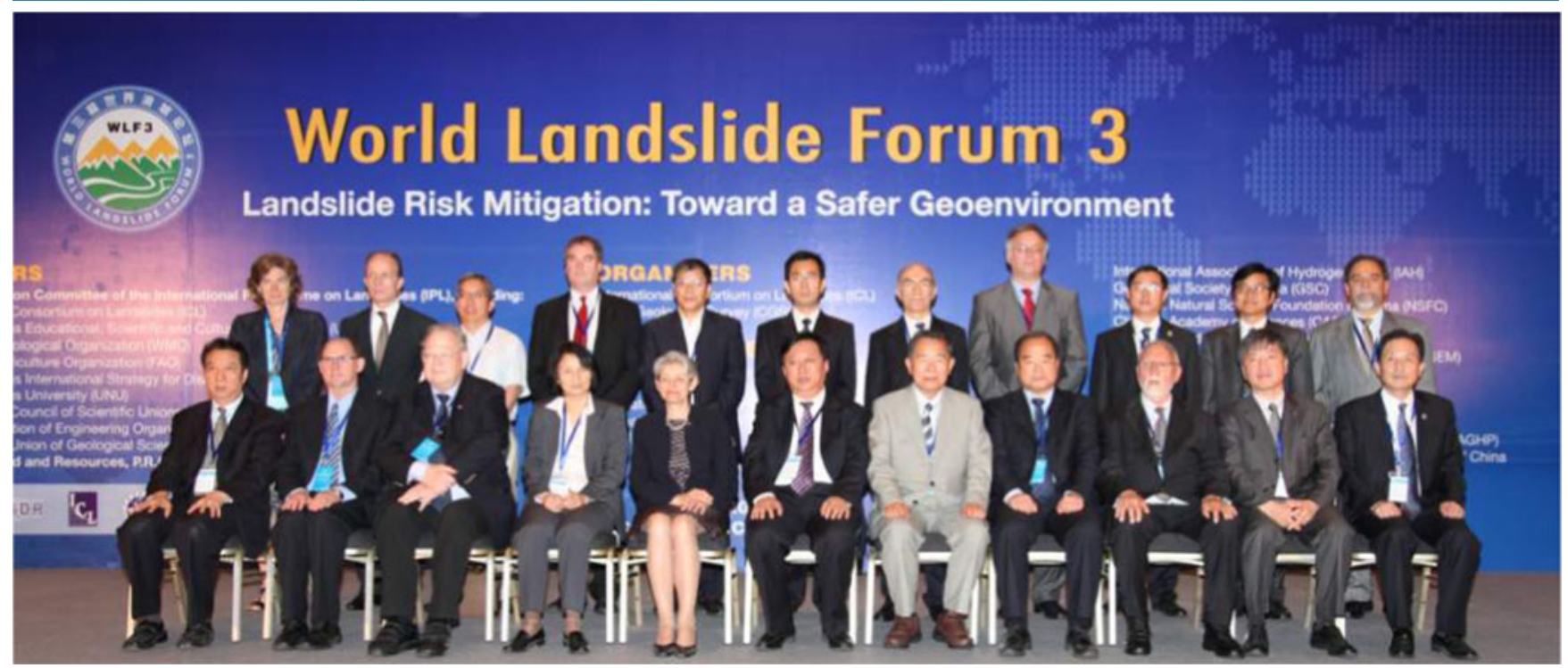

Fig. 1 Participants in the high-level panel discussion Initiative to create a safer geoenvironment toward WCDRR 2015 and forward at the World Landslide Forum 3, Beijing, 2014. The discussion was chaired by Hans van Ginkel (Former Rector of UNU). Participants are Ms. Irina Bokova (Director-General of UNESCO), representatives from UNISDR, WMO, ICSU/IRDR, China Geological Survey as well as ICL members. The 2014 Beijing Declaration Landslide Risk Mitigation: Toward a Safer Geoenvironment was adopted, which was the step for the ISDR-ICL Sendai Partnerships 2015-2025 (Sassa et al. 2015)

Yueping YIN, ICL President

Opening Address:

Hosting the Fourth World Landslide Forum in Slovenia

Miro CERAR, Prime Minister of the Republic of Slovenia*

Opening Speech:

UNESCO support to the foundation and progress of ICL-IPL

Activities

Irina BOKOVA (Director General of UNESCO)
After three forum lectures presented by Varnes Medal recipients and the best thematic issue editors, ICL is organizing a high-level panel discussion to implement the ISDR-ICL Sendai Partnerships 2015-2025 at the Cultural and Congress Centre Ljubljana on 30 May 2017. The plan for this discussion is the following:

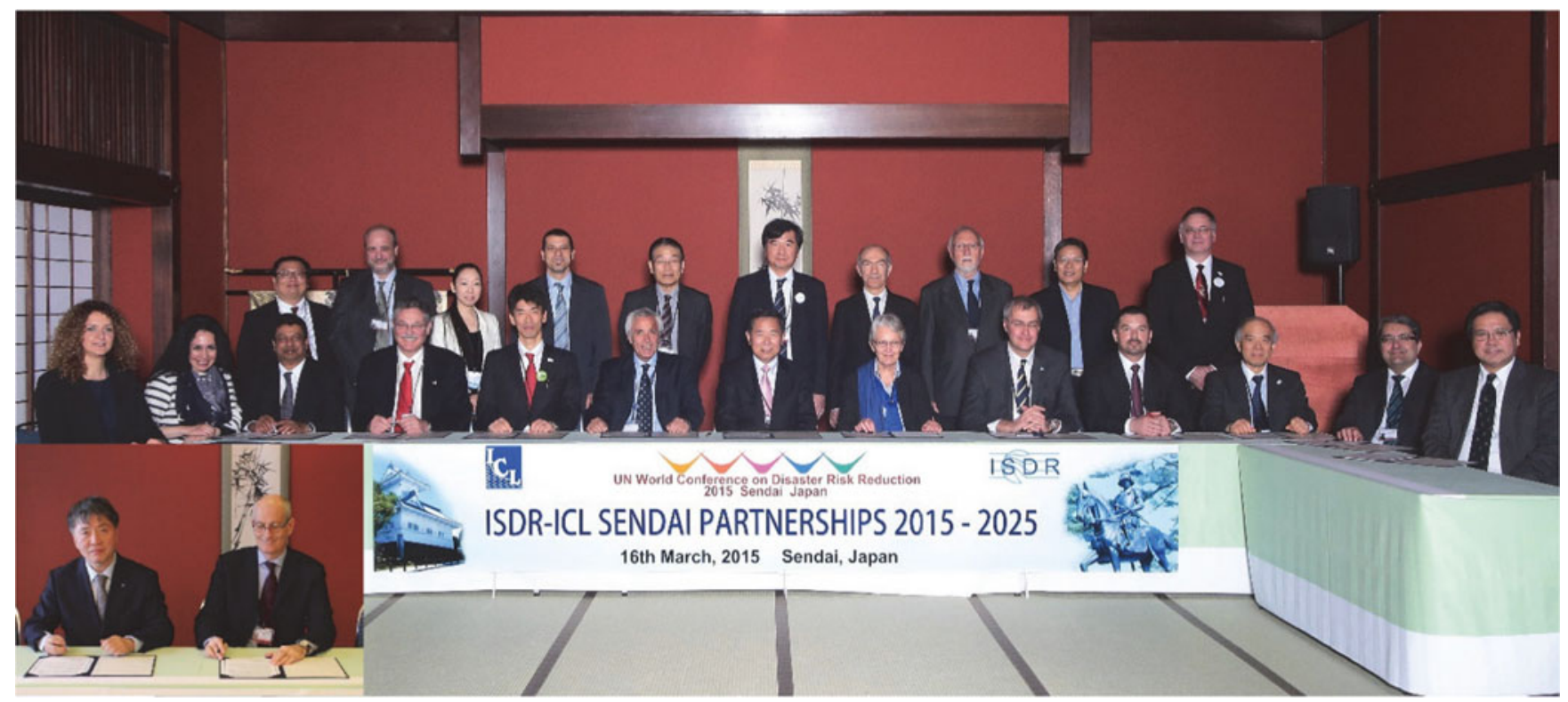

Fig. 2 The signers from the first 16 signatory organizations with ICL officers after the signing of the ISDR-ICL Sendai Partnerships 2015-2025 document (Sassa 2015) 
High-level panel discussion: Strengthening Intergovernmental Network and the International Programme on Landslides (IPL) for ISDR-ICL SENDAI PARTNERSHIPS 2015-2025 for global promotion of understanding and reducing landslide disaster risk

Objectives

ICL proposed the ISDR-ICL Sendai Partnerships 2015-2025 for global promotion of understanding and reducing landslide disaster risk at the 3rd WCDRR in Sendai, 2015 which was accepted and signed by 17 global and national stakeholders including the governments of Croatia, Italy, and Japan. This high-level panel discussion aims to strengthen networking with governments in landslide-prone countries and governments supporting landslide disaster risk reduction efforts in developing countries. Close cooperation within governments, United Nations Organizations, and International NGOs is necessary and effective to implement the ISDR-ICL Sendai Partnerships 2015-2025 and the International Programme on Landslides (IPL) as its infrastructure.

Keynote speech: Sendai Framework for Disaster Risk Reduction 2015-2030

by Robert Glasser (SRSG for Disaster Risk Reduction)*

Chair: Robert Glasser (Chief of UNISDR)*

Moderator: Kaoru Takara (ICL Treasurer, Director of Disaster Prevention Research Institute, Kyoto University)

- Presentation of ISDR-ICL Sendai Partnerships from UNISDR and ICL

- Panel presentations:

Representatives from 17 signatories of Partnerships and Governments officers from landslide-prone countries and Government officers supporting landslide disaster risk reduction efforts in developing countries.

- Discussion for strengthening commitments of different parties

- Conclusion of High-level Panel Discussion

( ${ }^{*}$ to be confirmed.)

Panelists will be invited from 17 signatory organizations of the Sendai Partnerships:

UN organizations of UNISDR (Pedro Basabe), UNESCO, WMO (Xu Tang), UNU (Jakob Rhyner), FAO. Governments of Japan (Kaoru Saito), Italy, Croatia, Slovenia, EU, and other countries

NGOs of ICSU (Irasema Alcantara-Ayala), WFEO (Toshimitsu Komatsu), IUGS (Roland Oberhänsli), IUGG (Alik IsmailZadeh), Science Council of Japan, Global Risk Forum (Walter Ammann)

Individuals: Badaoui Rouhban, Special Advisor to the Assistant Director-General of UNESCO for Natural Sciences. Satoru Nishikawa, Executive Director of Research of the Japan Center for Area Development Research).

Vol. 1 "Sendai Partnerships 2015-2025" book will be published within the five volumes of WLF4 (full color visual books) by Springer Nature. This volume will be published as an open-access book which may be read and downloaded free of charge by all people with internet access over the world. A hard-copy full-color print version of this volume will be distributed to all participants at WLF4 and sold to non-participants at an inexpensive price through the wide network of Springer Nature.
This volume includes three parts.

Part 1 Sendai Partnerships 2015-2025

Objectives and proposed activities of Sendai Partnerships

Keynote papers presented in the plenary sessions

Articles on the mission and activities the signatory organizations for panel discussion

Landslide Dynamics: ISDR-ICL Landslide interactive teaching tools.

Part 2 International Programme on Landslides (IPL)

Objectives and Infrastructures of IPL

UNESCO/KU/ICL UNITWIN Network supporting IPL

Landslides: Journal of the International Consortium on Landslides

WCoE activities, Activities of IPL projects, ICL Regional and thematic networks

Part 3 Accepted papers for Session Landslides and Society Legislation \& risk communication, local/regional communities, capacity building, and education

Part 4 Papers accepted for Student Session

Selected photos from the Landslide photo contest "Landslides and Mankinds"

Call for participation and cooperation to the Sendai Partnerships 20152025

The Sendai Partnerships 2015-2025 will contribute to the Sendai Framework for Disaster Reduction 2015-2030. Especially, it will fit to priority 1 Understanding Disaster risk as the base of other three priorities for Action, priority 2 Strengthening disaster risk governance to manage disaster risk, priority 3 Investing in disaster risk reduction for resilience, and priority 4 Enhancing disaster preparedness for effective response, and to «Build Back Better» in recovery, rehabilitation and reconstruction. ICL wishes to intensify the cooperation within 17 signatory organizations and other new organizations, governments and local governments, and private sectors. All of those entities and individuals who are willing to contribute to these partnerships are invited to this high-level panel discussion. Please access the webs of WLF4, ICL, and IPL and make contact with the ICL Secretariat.

One of core activities of the Sendai Partnerships, ICL is producing Landslide Dynamics: ISDR-ICL Landslide Interactive Teaching Tools. Landslide disasters are caused by landslide motion. The most important part of landslide studies for disaster risk reduction is the understanding of "Landslide Dynamics". All technologies gradually become out of date. Therefore, it is necessary to continually update and improve teaching tools to keep up with the progress of research and technology and the responses from users. The ongoing ICL teaching tools will be published on WEB to be continually updated and added to. The text tools are printed periodically. We aim to publish a thousand pages of text tools initially in 2017. The teaching tools contain six parts and four types as below:

A: The Landslide Interactive Teaching Tools contains six parts:

o. Handbook part (Definition of Landslides and Basic knowledges on landslide dynamics) 

1. Mapping and Site Prediction
2. Monitoring and Early Warning
3. Testing and Numerical Simulation
4. Risk Management and Others
5. Country Practices and Case Studies

B: The Landslide Interactive Teaching Tools contains four types of tools.

1. Text-tools consisting of original texts with figures.

2. PDF-tools consisting of already published reference papers, manuals, laws, and all supporting materials.

3. The third type are PPT-tools consisting of Powerpoint ${ }^{\circledR}$ files made for lectures.

4. Video-Tools

The teaching tools welcome the experiences in developing countries and case studies as well as new scientific knowledges for understanding landslides and new technologies to reduce landslide disasters such as early warning, hazard mapping and risk management. The entities and individuals who are willing to share their experiences, scientific knowledges and technologies to other parts of world are invited to contribute to the ISDR-ICL Landslide Interactive Teaching Tools. Please contact the secretariat ISDR-ICL teaching tools: icl-teaching-tool@iclhq.org.

WEBs and Emails of ICL, WLF4, and Teaching Tools:

ICL WEB: http://icl.iplhq.org/category/home-icl/

IPL WEB: http://iplhq.org/category/home/

WLF4 WEB: http://www.wlf4.org/

Email of ICL secretariat: secretariat@iclhq.org

Email of the secretariat of Teaching Tools: icl-teachingtool@iclhq.org
Acknowledgments

Landslide dynamics: ISDR-ICL Landslide Interactive Teaching Tools is a new development of the ICL Landslide Teaching Tool project in 2014 (He et al. 2014). This initial activity was supported by the UNESCO activity supporting fund of the Director-General Office for International Affairs of the Ministry of Education, Culture, Sports, Science and Technology (MEXT), Japan, and also supported by the International Programme on Landslides (IPL-175): Development of landslide risk assessment technology and education in Vietnam and other areas in the Greater Mekong Sub-region since 2012. This project is one of SATREPS (Science and Technology Research Partnership for Sustainable Development Programme) Project which is financially supported by the Science and Technology Research Partnership for Sustainable Development Programme (SATREPS) of the Japan Science and Technology Agency (JST) and the Japan International Cooperation Agency (JICA). This ISDR-ICL Landslide Interactive Teaching Tools could not have started without the preceding ICL Teaching Tools project. ICL appreciates all of funding agencies and cooperating researchers for this initial teaching tools.

\section{References}

He B, Sassa K, McSaveney M, Ngai 0 (2014) Development of ICL landslide teaching tools. Landslides 11(1):153-159

Sassa K (2006) 2006 Tokyo Action Plan-strengthening research and learning on landslides and related earth system disasters for global risk preparedness. Landslides 3(4):361-369

Sassa K (2012) ICL Strategic plan 2012-2021-to create a safer geoenvironment. Landslides 9(2):155-194

Sassa K (2015) ISDR-ICL Sendai partnerships 2015-2025 for global promotion of understanding and reducing landslide disaster risk. Landslides 12(4):631-640

Sassa K, Yin Y, Canuti P (2015) The Third World Landslide Forum, Beijing, 2014. Landslides 12(1):177-192

\section{K. Sassa ( $\bullet)$}

International Consortium on Landslides,

138-1, Tanaka Asukaicho, Sakyo-ku, Kyoto, 606-8226, Japan

e-mail: sassa@iclhq.org 